\title{
Genome-wide characterization of aspartic protease (AP) gene family in Populus trichocarpa and identification of the potential PtAPs involved in wood formation
}

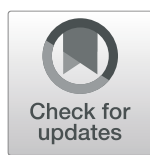

Shenquan Cao ${ }^{1}$, Mengjie Guo ${ }^{1}$, Chong Wang ${ }^{1}$, Wenjing $\mathrm{Xu}^{1}$, Tianyuan Shi ${ }^{1}$, Guimin Tong ${ }^{1}$, Cheng Zhen ${ }^{1}$, Hao Cheng ${ }^{1}$, Chuanping Yang ${ }^{1 *}$, Nabil Ibrahim Elsheery ${ }^{2}$ and Yuxiang Cheng ${ }^{1 *}$ (i)

\begin{abstract}
Background: Aspartic protease (AP) is one of four large proteolytic enzyme families that are involved in plant growth and development. Little is known about the AP gene family in tree species, although it has been characterized in Arabidopsis, rice and grape. The AP genes that are involved in tree wood formation remain to be determined.

Results: A total of 67 AP genes were identified in Populus trichocarpa (PtAP) and classified into three categories (A, B and C). Chromosome mapping analysis revealed that two-thirds of the PtAP genes were located in genome duplication blocks, indicating the expansion of the AP family by segmental duplications in Populus. The microarray data from the Populus eFP browser demonstrated that PtAP genes had diversified tissue expression patterns.

Semi-qRT-PCR analysis further determined that more than 10 PtAPs were highly or preferentially expressed in the developing xylem. When the involvement of the PtAPs in wood formation became the focus, many SCWrelated cis-elements were found in the promoters of these PtAPS. Based on PtAP promoter: GUS techniques, the activities of PtAP66 promoters were observed only in fiber cells, not in the vessels of stems as the xylem and leaf veins developed in the transgenic Populus tree, and strong GUS signals were detected in interfascicular fiber cells, roots, anthers and sepals of PtAP17 promoter:: GUS transgenic plants. Intensive GUS activities in various secondary tissues implied that PtAP66 and PtAP17 could function in wood formation. In addition, most of the PtAP proteins were predicted to contain $\mathrm{N}$ - and (or) O-glycosylation sites, and the integration of PNGase $\mathrm{F}$ digestion and western blotting revealed that the PtAP17 and PtAP66 proteins were N-glycosylated in Populus.
\end{abstract}

Conclusions: Comprehensive characterization of the PtAP genes suggests their functional diversity during Populus growth and development. Our findings provide an overall understanding of the AP gene family in trees and establish a better foundation to further describe the roles of PtAPs in wood formation.

Keywords: Populus trichocarpa, Aspartic protease, Gene family, Promoter activity, Secondary cell wall, Glycosylation

\footnotetext{
*Correspondence: yangcp@nefu.edu.cn; chengyuxiang@nefu.edu.cn

'State Key Laboratory of Tree Genetics and Breeding, Northeast Forestry

University, Harbin, Heilongjiang, China

Full list of author information is available at the end of the article
}

(c) The Author(s). 2019 Open Access This article is distributed under the terms of the Creative Commons Attribution 4.0 International License (http://creativecommons.org/licenses/by/4.0/), which permits unrestricted use, distribution, and reproduction in any medium, provided you give appropriate credit to the original author(s) and the source, provide a link to the Creative Commons license, and indicate if changes were made. The Creative Commons Public Domain Dedication waiver (http://creativecommons.org/publicdomain/zero/1.0/) applies to the data made available in this article, unless otherwise stated. 


\section{Background}

Aspartic proteases (APs; Enzyme Commission 3.4.23) are a group of proteolytic enzymes that exist widely in bacteria, fungi, animals and plants. They are a relatively simple class of enzymes that usually contain two aspartic acid residues within the conserved Asp-Thr/Ser-Gly motifs and are crucial for catalytic activity [1]. Generally, APs are most active under acidic $\mathrm{pH}$ ( $\mathrm{pH} 2-6)$ and are specifically inhibited by pepstatin A. Unlike bacteria and fungi genomes with fewer family members [2-4], plant AP gene families are much larger. Fifty-one potential APs were found initially in Arabidopsis (Arabidopsis thaliana) and divided into three categories: typical APs, nucellin-like APs and atypical APs [5]. Subsequently, the Arabidopsis AP family was further enlarged to approximately 69 members [6]. Afterwards, 96 OsAPs and $50 \mathrm{VvAPs}$ were identified in rice (Oryza sativa L.) and grape (Vitis vinifera L.) genomes, respectively $[7,8]$. Although APs have been found in plants, knowledge of their functions is still lacking.

The first well-studied plant AP was phytepsin from barley (Hordeum vulgare), which possesses a plant-specific insert (PSI) domain and is localized in the vacuole; possibly, it plays a role in the active autolysis of tracheary elements and sieve cells $[9,10]$. In the last decade, a limited number of studies indicated important roles for the APs in protein processing, signal transduction and stress responses $[5,11$, 12]. Tobacco (Nicotiana tabacum) DNA-binding protease CND41 was involved in Rubisco turnover during leaf senescence [13]. OsAP65 was speculated to degrade a specific substrate and produce some substances necessary for pollen germination and pollen tube growth [14]. Arabidopsis nucellin-like aspartic protease APCB1 with a molecular cochaperone was revealed in the processing of $\mathrm{Bcl}-$ 2-ASSOCIATED ATHANOGENE6 (BAG6) to trigger autophagy and defense resistance [15]. In Arabidopsis and rice, the extracellular AP (CONSTITUTIVE DISEASE RESISTANCE1, CDR1) mediated a peptide signal system involved in activation of inducible resistance mechanisms $[16,17]$. In contrast, an apoplastic AP (APOPLASTIC EDS1-DEPENDENT1, AED1) suppressed systemic acquired resistance (SAR) by a feedback mechanism [18]. Another AP (ASPARTIC PROTEASE IN GUARD CELL1, ASPG1) participated in abscisic acid (ABA)-dependent responsiveness, and its overexpression could confer drought avoidance in Arabidopsis [19]. An additional report revealed the involvement of ASPG1 in Arabidopsis seed germination, which was associated with the degradation of seed storage proteins (SSPs) and regulation of gibberellic acid (GA) signaling [20].

In addition, APs play an important role in plant programmed cell death (PCD). In rice, S5 participated in indica-japonica hybrid fertility and could stimulate endoplasmic reticulum (ER) stress, giving rise to $\mathrm{PCD}$ in the embryo sac [21, 22]. AtMYB80 and rice EAT1 controlled tapetum PCD by targeting the downstream aspartic protease genes AtUNDEAD and OsAP25/OsAP37, respectively. Silencing the expression of AtUNDEAD caused the premature tapetal PCD and resulted in pollen PCD [23]. Overexpressing OsAP25 or OsAP37 induced extensive cell death or premature death in the Arabidopsis tapetum [24]. Moreover, aspartyl protease PROMOTION OF CELL SURVIVAL1 (PCS1), as an anti-cell-death component, played crucial roles in embryonic development and reproduction processes and its loss-of-function mutation caused degeneration of gametophytes and excessive cell death in developing embryos [25]. In addition, two glycosylphosphatidylinositol (GPI)-anchored, aspartic protease $A 36$ and $A 39$ double mutants displayed unanticipated PCD in the pollen [26]. However, little is known about the AP gene family in tree species. The trees evolve many specific traits (such as large wood formation and perennial growth) that are different from herbaceous plants. Wood formation is complex process, with sequential events that include vascular cambium cell differentiation, cell elongation, secondary cell wall (SCW) thickening and PCD [27]. To date, the roles of plant APs in secondary cell wall formation or wood formation are not identified or reported in plants including the trees. In recent years, several AP proteins were recognized in plant cell wall proteomics [28]. In addition, cysteine proteases (CEP1, XCP1/2 and AtMC9) have been identified to function in SCW or PCD during secondary growth [29-31]. Hence, the AP genes that are involved in wood formation remain to be determined, and whether one to several APs might be as the indicative genes in the process of Populus wood formation arouses our interests.

Poplar is a fast-growing tree with high capacity for vegetative propagation, which has a large biomass accumulation in terrestrial ecosystem. They are extensively used for the pulp and paper industry, reforestation of lands and bioenergy feedstocks. As a model tree, Populus trichocarpa has attracted much attention, particularly by the availability of its genome sequences [32], which gave us an opportunity to carry out a comprehensive genome-wide analysis for exploring the potential functions of the AP genes in poplar. In the present study, we identified 89 P. trichocarpa AP genes, of which 67 PtAPs possess the complete ASP domain. Analysis of the phylogeny, gene organization, conserved motifs, gene duplications and expression patterns were carried out in this gene family. Based on SCW-related cis-elements and promoter:: $\beta$-glucuronidase (GUS) expression analyses, some PtAP members were proposed to function in wood formation. Our study provides a significant foundation for further investigations into their potential roles in Populus growth and development and a better understanding of the AP gene family in a tree species. 


\section{Results}

Genome-wide identification and phylogenetic analysis of Populus AP gene family

To identify the AP family members in Populus, systematic BLASTP analysis was performed using previously reported Arabidopsis AP protein sequences as the queries. The 92 nonredundant candidate sequences were identified in the P. trichocarpa genome (http://www.phytozome.net) - Among them, 89 candidate sequences have the perfect open reading frame (ORF). Subsequently, these candidate AP genes were further confirmed by SMART and NCBICDD tests, and 67 genes were found to have the complete ASP domain (PF00026) with two conserved aspartic acid catalytic residues (Additional file 1 and Additional file 2). For further convenience, these 67 Populus AP genes were named PtAP1 to PtAP67 based on their order on the chromosomes (Additional file 1). The remaining 22 genes (named as PtAP-Like1 to 22) were eliminated in this study because they were partial or absent in the ASP domain through manual inspection (Additional file 3). The corresponding information for the PtAP genes, including gene symbol, locus, group, protein length (aa), molecular weight $(\mathrm{MW})$, the predicted glycosylation sites and the proposed protein subcellular localization were shown in Additional file 1, Additional files 4 and 5.

To investigate the phylogenetic relationship, we constructed a phylogenetic tree with the 67 PtAPs, 30VvAPs and 51 AtAPs, as well as other known AP proteins (Nucellin, CND41 and cardosin A). The results indicate that these 67 PtAPs can be divided into three categories (A, B and C; Fig. 1), similar to those described in Arabidopsis, grape and rice $[5,7,8]$. Category A included 7 PtAPs and cardosin A. These proteins with the PSI domain (including SapB_1 and SapB_2) represent typical APs (Additional files 6 and 7), revealing more typical APs in Populus than those in Arabidopsis. In category B, 6 PtAPs consisted of nucellin-like APs, which contain two cysteines within the highly conserved sequences QCDYE and GCGYDQ [5]. The rest of the 54 PtAPs clustered into category $\mathrm{C}$ as atypical APs. Additionally, the dendrogram showed the closely related orthologous APs among Populus, grape and Arabidopsis (for instance, PtAP59-64/VvAP5-8/AT5G10760-10,770),

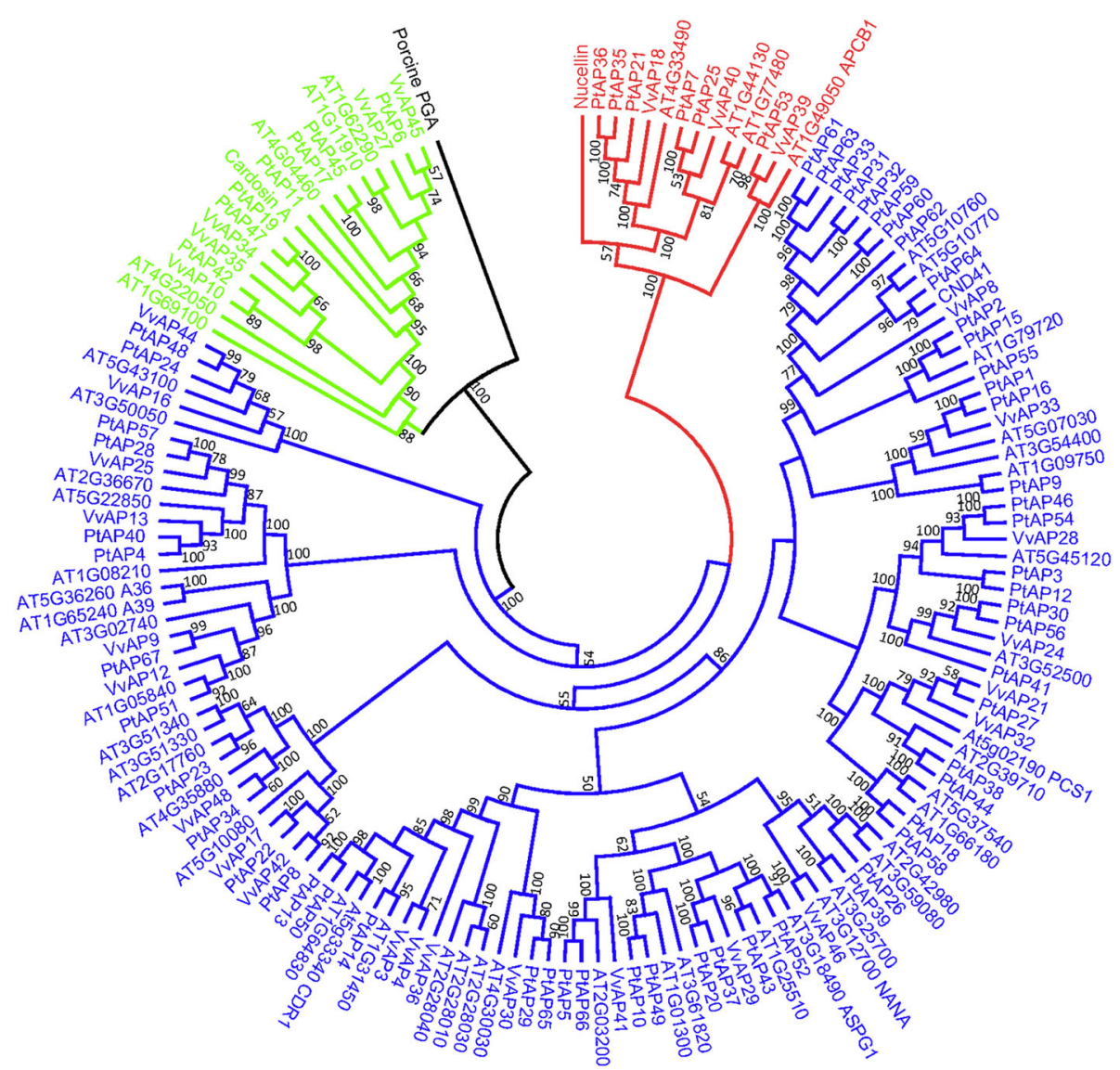

Fig. 1 Phylogenetic analysis of Populus, grape and Arabidopsis AP protein sequences. Sixty-seven PtAPs, 30 VvAPs and 51 AtAPs were aligned with Clustal X 2.0, and the phylogenetic tree was constructed using the neighbor-joining method with 1000 bootstrap replication. Porcine pepsin A was used as the outgroup. Nucellin (U87148), CND41 (D26015) and cardosin A (CAB40134) were convenient to compare and define categories of the APs. All AP proteins were classified into three categories with different colors 
suggesting that many ancestral AP genes existed prior to the divergence of Populus, grape and Arabidopsis.

\section{Gene structures and conserved motifs}

In addition, we analyzed the exon/intron arrangements of the 67 PtAP genes based on their phylogenetic tree (Fig. 2a). The closest genes shared similar gene structures in terms of either the intron numbers or exon lengths, but PtAP genes in different categories exhibited different exon/intron structural features. Most genes from the category B had 8 exons except PtAP53, which contained 10 exons, similarly to a nearby subgroup. In the category $C$, the gene structures appeared to be more variable, with the exon numbers ranging from 1 to 12 , but the number of exons was similar within each subgroup. Additionally, these results indicated a strong correlation between the phylogeny and exon/intron structures (Fig. 2b).

To gain insight into the specific regions of the PtAP proteins, we analyzed the distribution of conserved motifs, and 20 motifs were captured by the MEME online tool (Fig. 2c and Additional file 8). The length of the motifs ranged from 10 to 50 amino acids, and the number of conserved motifs varied from 9 to 15 in each of the PtAPs. Motifs 1, 2, 3, 4, 5, 12 and 15 appeared in

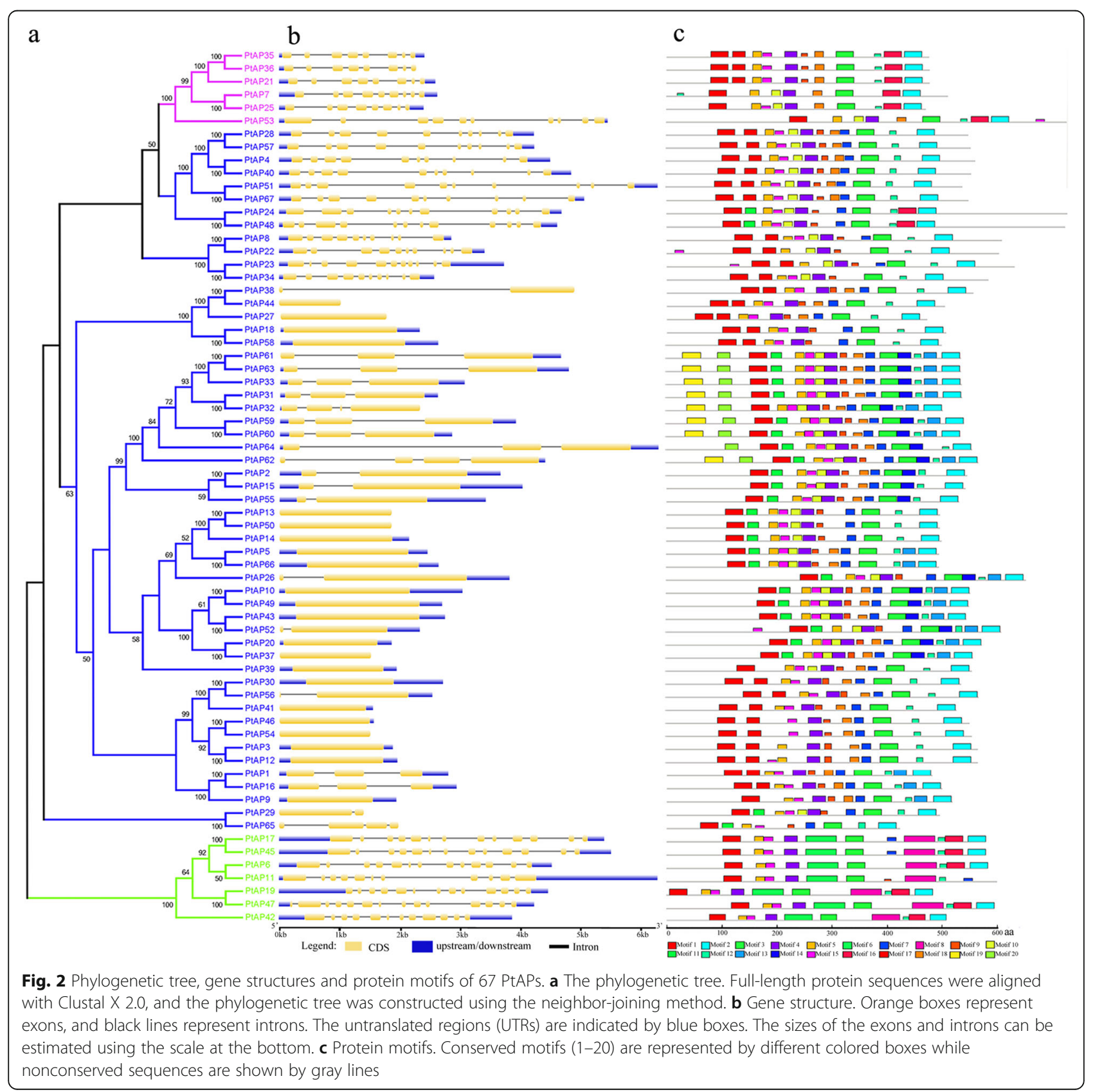


nearly all members of PtAPs, whereas motifs 6 and 8 were specific to category A, and motifs $11,13,1419$ and 20 were found only in category C. Most of the PtAP proteins within each subgroup showed highly conserved motifs and different subgroups contained distinct conserved motifs.

\section{Chromosomal location and gene duplications}

We mapped 67 PtAPs on chromosomes by the PopGenIE v3 database (http://www.popgenie.org/). As shown in Fig. 3, the physical locations of these PtAPs on chromosomes were scattered and uneven. Chromosome 5 had the maximum number (eight members) of PtAP genes, followed by chromosomes 6 and 18, each with seven PtAP genes. Three PtAP genes were simultaneously distributed on chromosomes 10,15 , and 16, whereas chromosomes $11,12,13$, and 17 had only one.

Segmental and tandem duplications are the main mechanisms leading to gene family expansion [33]. To elucidate the expanded mechanism of the PtAP gene family, we used duplicated blocks, which were established in a previous study [32], to determine the potential segmental duplications. As illustrated in Fig. 3, 30 gene duplication pairs corresponded to 42 PtAP genes. Among them, some subgroups of PtAPs were reciprocal duplication genes, such as PtAP4/28/40/57, PtAP7/21/25/35, PtAP27/38/44 and PtAP30/41/56, implying that they might share a common ancestral gene. Moreover, PtAP39, PtAP50 and PtAP51 were duplicated on the corresponding blocks, but these duplicates (Potri.010G130100, Potri.002G188800 and PtAP-Like4, respectively) were incomplete or had lost the ASP domain. In addition, approximately 18\% (12 of
67) of the PtAP (PtAP6, 9, 11, 13, 14, 26, 29, 42, 53, 55, 65, and 67) genes were located outside of any duplicated blocks. Generally, a gene cluster is the result of gene tandem duplication [34]. Here, we found that some PtAP genes were adjacent to each other (Fig. 3 and Additional files 1). For instance, PtAP31 to 33, PtAP35/36, and PtAP59 to 64 were located sequentially in tandem on chromosomes 6, 7, and 18, respectively, implying that these genes might arise from recent tandem duplication events. These results indicate that both tandem and segmental duplications play a crucial role in the expansion of the PtAP gene family.

Additionally, we estimated the nonsynonymous substitution rate $(\mathrm{Ka})$, the synonymous substitution rate $(\mathrm{Ks})$ and the $\mathrm{Ka} / \mathrm{Ks}$ ratio based on phylogenetic analysis and chromosomal distribution of PtAPs. The results showed that the approximate dates of the duplication events took place from 114.09 million years ago (Mya) to 9.47 Mya (Additional file 9). In view of the data showing divergence between Populus and Arabidopsis approximately 100 to 120 Mya, almost all the PtAP segmental duplications occurred after the Populus and Arabidopsis split. The $\mathrm{Ka} / \mathrm{Ks}$ ratios of gene pairs were $<1.0$, implying that these PtAP gene pairs were under the influence of purifying selection after duplication.

\section{Diversified expression patterns of PtAP genes}

To analyze the expression profiles of the PtAP genes, we reviewed their transcript abundance patterns across multiple tissues and organs (including root, developing xylem, young leaf, mature leaf, male catkin and female catkin) using data retrieved from the Populus eFP browser with

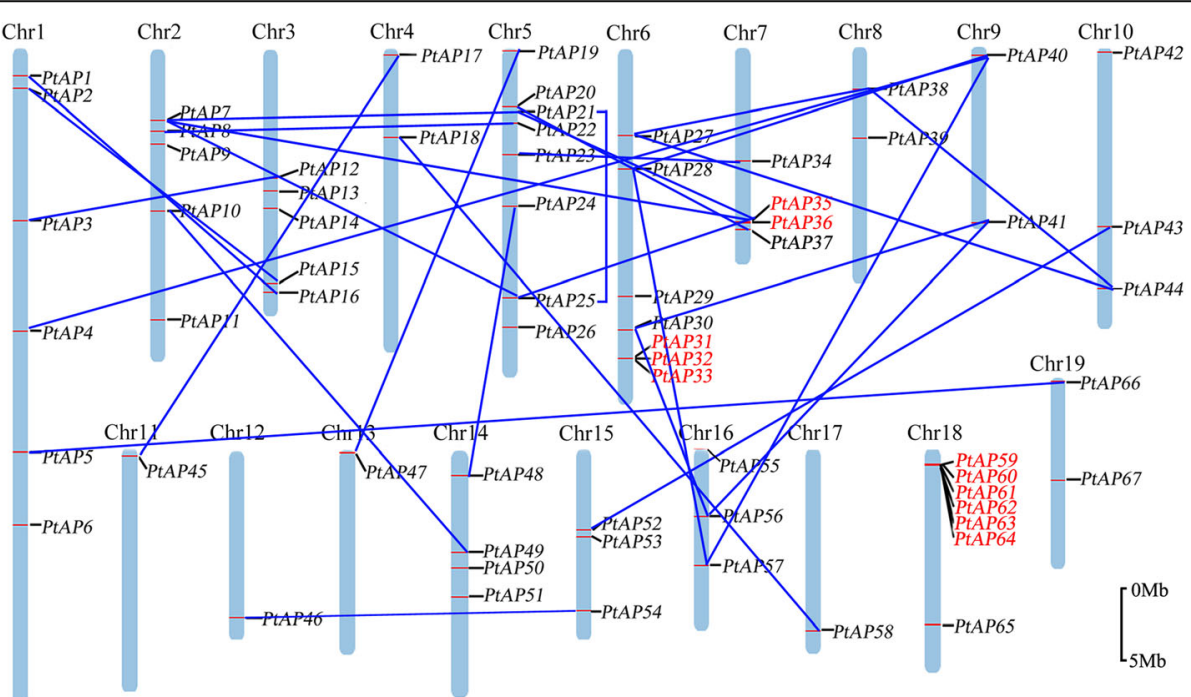

Fig. 3 Chromosomal locations and duplicated gene pairs of 67 PtAPs. Each was mapped to the chromosome based on its physical location. The chromosome number (Chr01-Chr19) is indicated at the top. The segmental duplicated gene pairs were connecting with a solid blue line, and tandem duplicated genes were outlined with red color. The scale bar represents $5.0 \mathrm{Mb}$ 
corresponding probe sets (Additional file 10). In total, 57 PtAP genes were found in the microarray data (Additional file 11). The heat map demonstrated that most PtAPs had tissue-specific or preferential expression patterns (Fig. 4). PtAP66 was specifically expressed in developing xylem; PtAP17 and PtAP64 were preferentially expressed in developing xylem, root and catkin; PtAP1 and 45 were highly expressed in young leaf, root and developing xylem; PtAP21, 44 and 51 were expressed preferentially in catkins; and PtAP6/11 and PtAP19/47 showed higher expression level in root and young leaf, respectively. These data suggest that the PtAPs may be involved in multiple processes during Populus growth and development.

In addition, 12 PtAP genes with a higher eFP value (eFP $>1000)$ of developing xylem were selected to examine their expression levels by semi-qRT-PCR in phloem, cambium, developing xylem, apical bud, young leaf, mature leaf and petiole (Fig. 5a). Most PtAP gene expression profiles were consistent with the microarray data, whereas the expression levels of PtAP30 and PtAP4O in xylem were slightly lower than those in young leaves. This result may be due to an error caused by different standards of materials. In addition, the PtAP1 was highly expressed in the apical bud, and PtAP10 and 45 were preferentially expressed in the cambium (Fig. 5a), suggesting that they may function in these tissues. Furthermore, qRT-PCR analysis showed expression levels of 12 PtAP genes in different tissues (Fig. 5c), which is in agreement with the results from semi-qRT-PCR analysis.

We further explored the relationships of these PtAP genes that were highly expressed in xylem with the secondary cell wall formation. Since the 1st to 4th internodes (IN) showed primary growth with stem elongation, and the 5th IN below initiated the gradually lignified SCWs [35], we examined their expression levels in IN 1, 2, 3, 4, 5, 6, 9 and 12. As shown in Fig. 5b, the levels of PtAP1 and PtAP3O in the stem elongation region were dominant and tapered off as the stem secondary growth began. In contrast, PtAP10, 17, 45, 53, 64 and 66 showed the opposite trend in the expression levels, which correlated well with the switch to stem radial growth following activation of secondary growth. Our results indicate that these genes are likely to function in Populus secondary growth or wood formation.

\section{Analysis of the cis-elements related to SCW formation in the promoter region of the PtAPs}

Transcriptional networks are responsible for the coordinated regulation of secondary wall biosynthetic gene expression during secondary wall formation. We presume that PtAPs may be in the downstream of transcriptional network regulating wood secondary wall formation and be targets of secondary wall-regulated transcription factors. In view of this, we analyzed the cis-elements related to

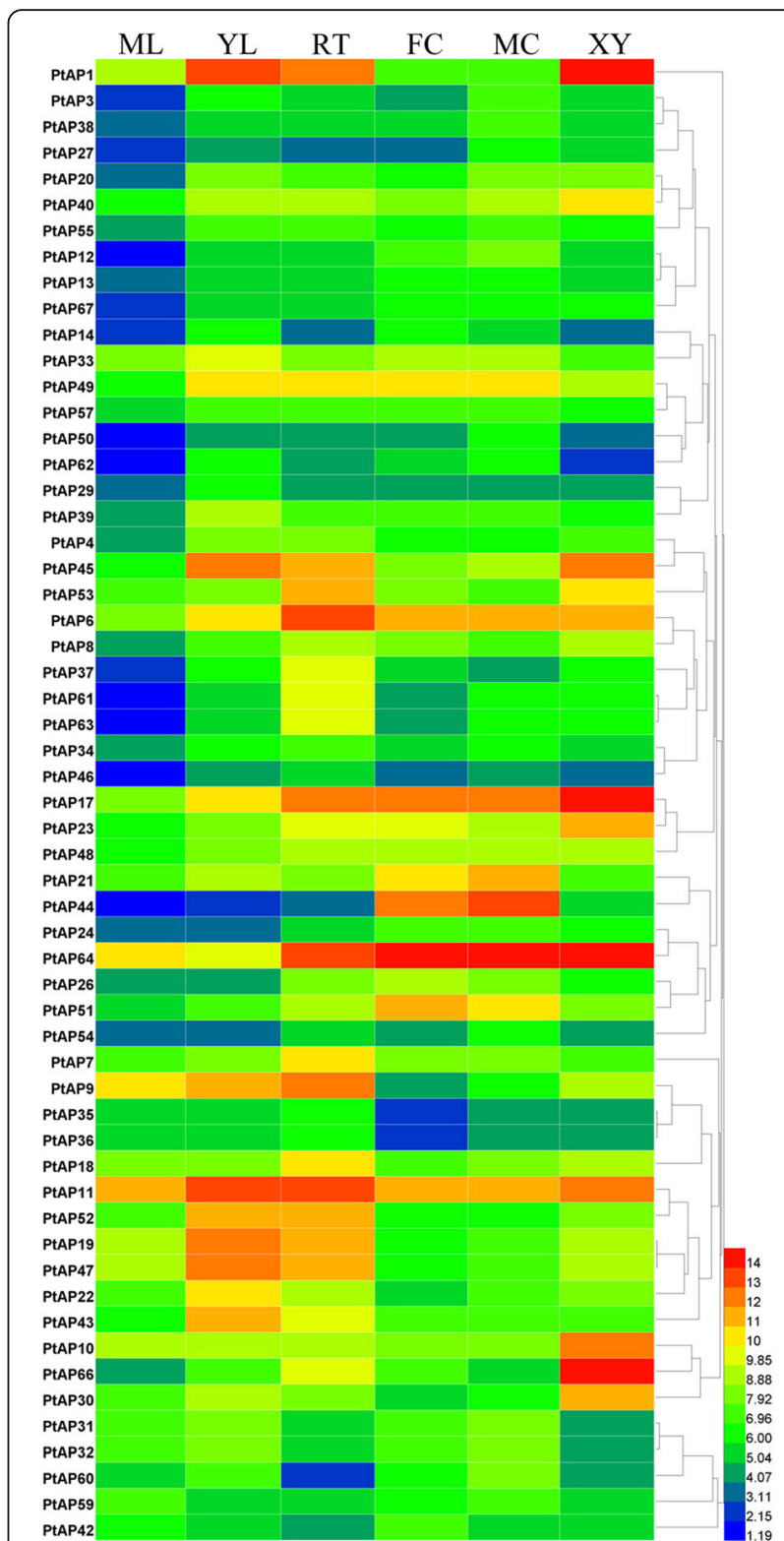

Fig. 4 Hierarchical clustering of expression profiles of PtAPs in different tissues. The microarray data were downloaded from the Poplar eFP browser. Color scale at the right of the dendrogram represents log2 expression values. $M L$, mature leaf; $Y L$, young leaf; RT, root; FC, female catkin; $M C$, male catkin; $X Y$, xylem

SCW formation in the promoter regions of the 26 PtAPs (xylem eFP $>1000$ and corresponding replication genes) with high or preferential expression levels in the developing xylem. As shown in Fig. 6, a total of 10 cis-elements were herein identified in these PtAPs. Most promoter regions (3000 bp) of these genes (except for PtAP34, 49, 57, 59 and 64) had cis-element SNBE. PtAP4, 5, 6, 11, 23, 30, $34,40,41,45,49,57,59,60$ and 64 contained cis-element M46RE. Nevertheless, cis-element TERE existed only in the promoter region of PtAP30. In addition, the promoter 


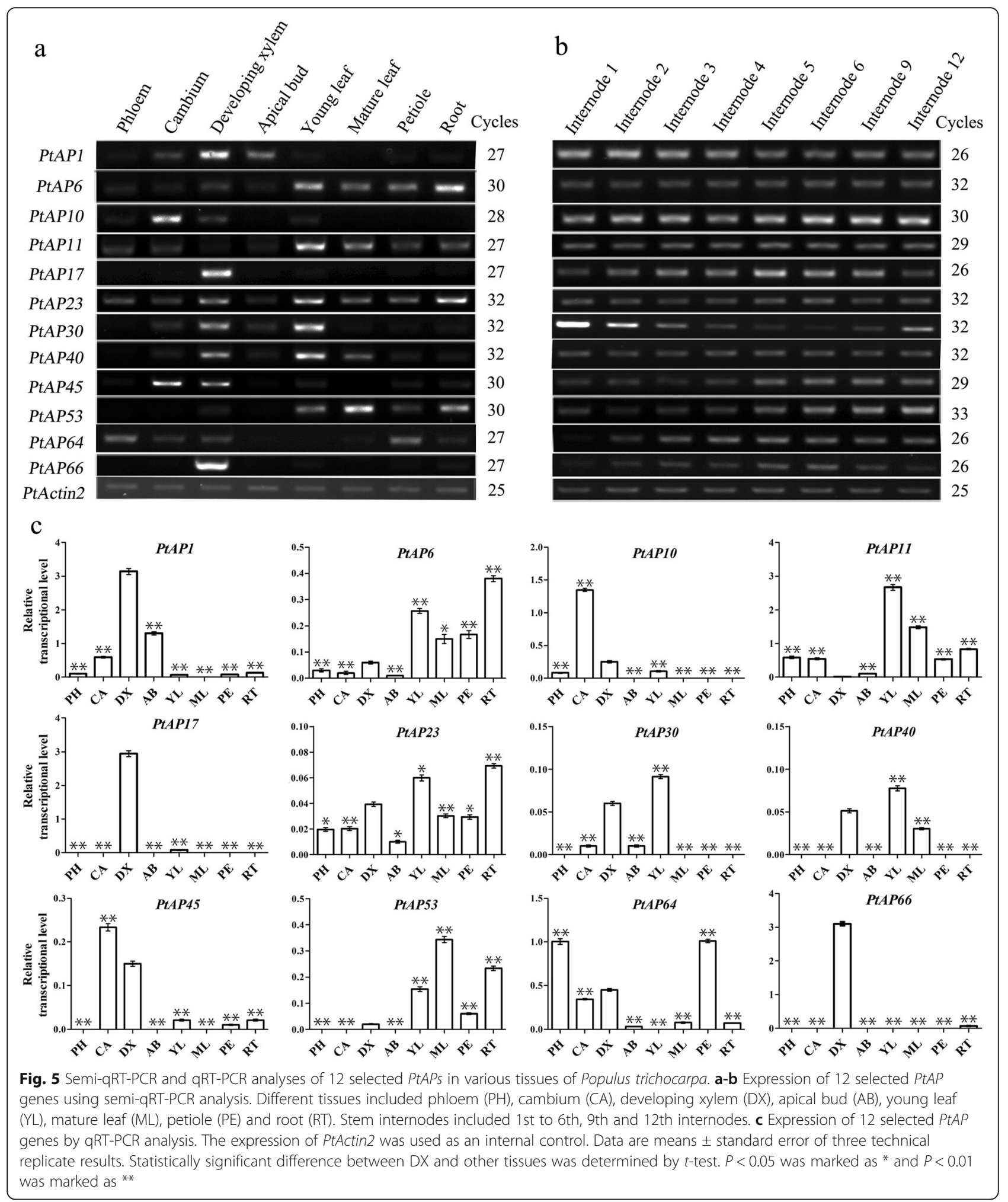




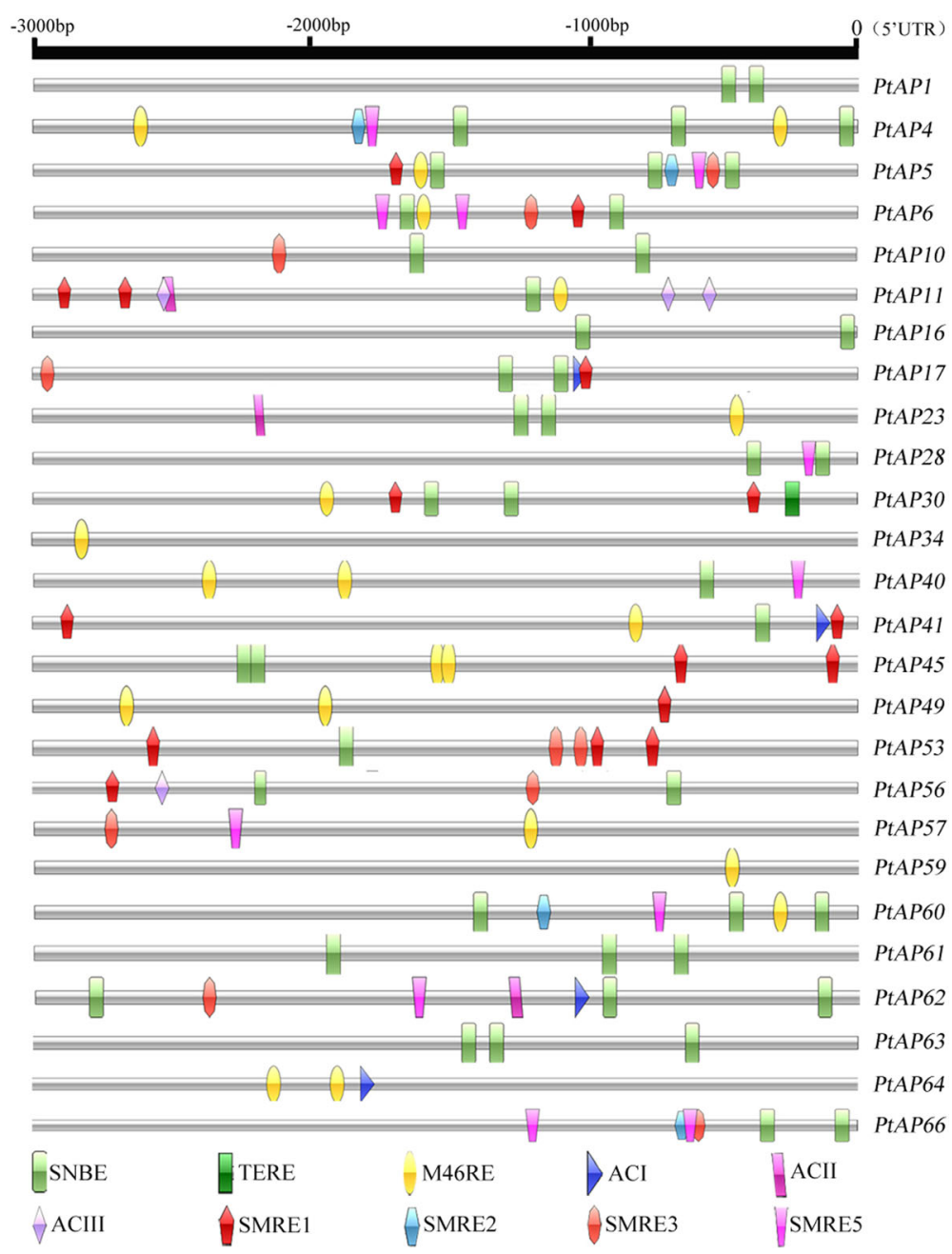

Fig. 6 Analysis of secondary cell wall (SCW)-related cis-elements in promoters of 26 PtAP genes. The 3000 bp promoter regions (upstream DNA sequence of the 5'-UTR) of each PtAP gene were analyzed for SCW-related cis-elements. Different cis-elements were indicated by different colored diagrams

regions of PtAP5, 6, 11, 17, 30, 41, 45, 49, 53 and 56 had the cis-elements SMRE1, and PtAP17, 41, 62 and 64 contained the cis-elements ACI. To date, the SNBE, M46RE, TERE, SMRE and AC elements have been identified as being involved in SCW formation and (or) PCD during xylem development [36-41]. Therefore, our data indicated that these PtAPs should function in Populus wood formation.

\section{Promoter:GUS-based analysis of the SCW-related PtAPs in transgenic plants}

Compared with other PtAPs, the PtAP17 and PtAP66 are most highly and specially expressed in the xylems (Fig. 5). In addition to this, PtAP17 and PtAP66 are predicted to be localized in vacuole and cell wall (Additional file 1), suggesting that they may be involved in different biological process during wood formation. Based on these, we firstly focused on the activities of PtAP17 and PtAP66 promoters using PtAPpro::GUS approach. In PtAP66pro::GUS lines,
GUS activity was intensively detected in secondary phloem fibers, developing xylems, leaf main veins and root steles (Fig. 7f-j), which are the main parts of the secondary vascular system. Especially strong GUS signals were localized in the fibers, not in the vessels, of stems developing xylem and leaf main veins (Fig. $7 \mathrm{f}$ and i). To confirm the reliability of this, we further examined the activity of PtAP66 promoter in transgenic Arabidopsis. As expected, GUS activities were still detected in main secondary vascular tissues (Fig. 8a-i), and the interfascicular fibers, not vessels in the metaxylem, displayed strong GUS activities (Fig. 8i). Interestingly, although PtAP5pro::GUS in transgenic Populus was moderately expressed on the level, a GUS signal could be observed in the vessels, but not in the fibers, of the developing xylems (Fig. 7k-1). PtAP66 and PtAP5, a pair of segmental duplicated genes (Fig. 3), showed different expression patterns of their promoters in the developing xylems, suggesting the distinct roles of 

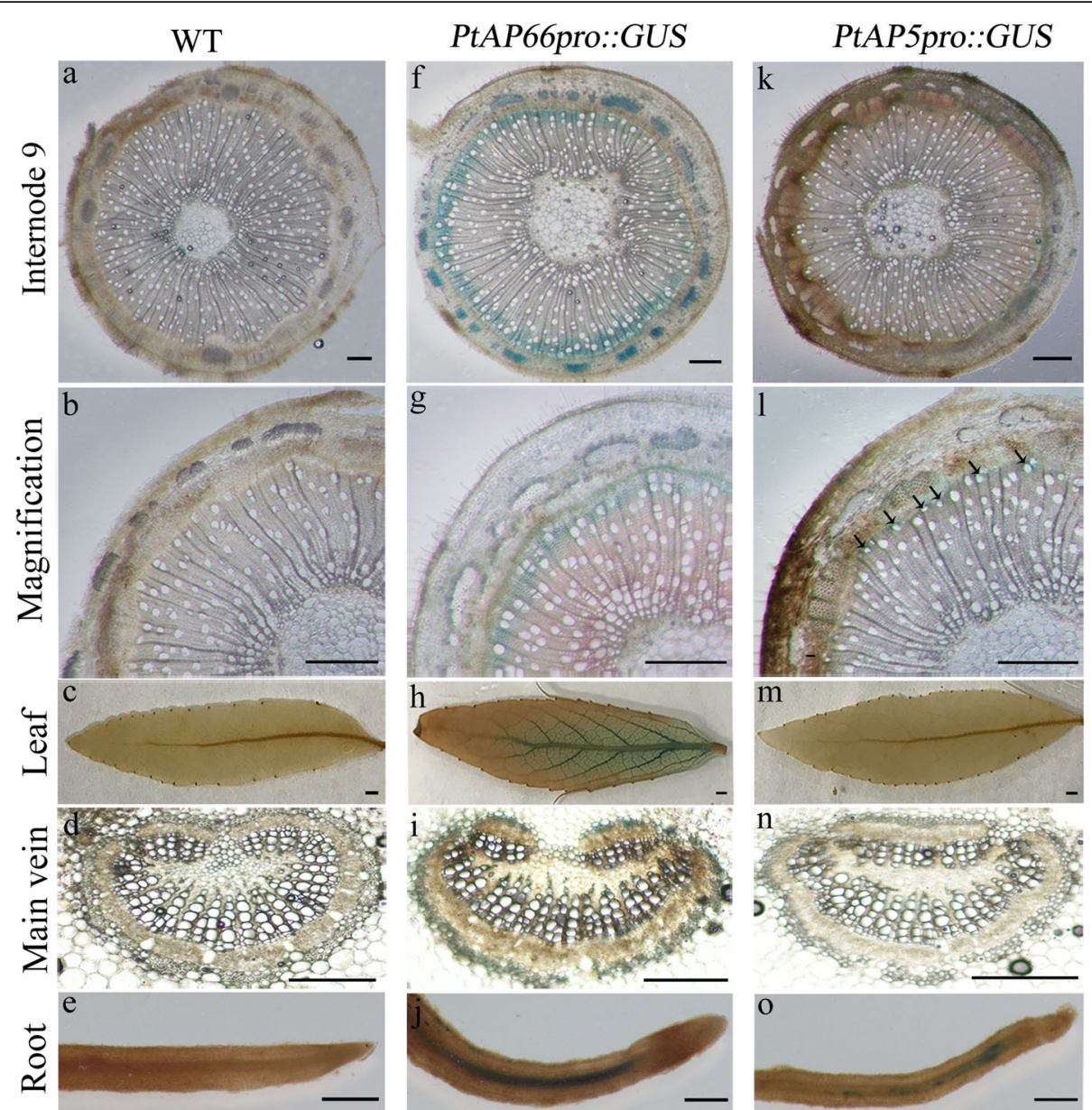

Fig. 7 GUS assay of transgenic Populus driven by PtAP66 and PtAP5 promoters, respectively. a-e Wild type (WT) as a negative control; $\mathbf{f}-\mathbf{j}$ PtAP66promoter::GUS; $\mathbf{k}-\mathbf{o}$ PtAP5promoter::GUS. a-b, $\mathbf{f - g}, \mathbf{k}-\mathbf{I}$ Cross-sections of 9th stem internodes from 60-day-old WT, PtAP66promoter::GUS and PtAP5promoter::GUS young trees, respectively. $\mathbf{d}$-n Cross-sections of leaf main veins from these young trees, respectively. Arrows indicate xylem vessels. Scale bars, $500 \mu \mathrm{m}$

PtAP66 and PtAP5 in the wood formation. Additionally, we examined the activity of the PtAP17 promoter in transgenic Arabidopsis plants (Fig. 8j-r). Intensive GUS signals were observed in stem interfascicular fibers, leaf main veins, and root steles of the PtAP17pro::GUS transgenic lines, as shown in the PtAP66pro::GUS transgenic lines. Moreover, GUS activities were detected in the root tip, anther and sepal of the PtAP17pro::GUS transgenic lines, which were distinct with the activities of the PtAP66 promoter (Fig. 8c and e). These data also revealed that PtAP17 should be involved in SCW formation.

\section{$\mathrm{N}$-glycosylation analysis of the PtAP proteins}

The potential N- and O-glycosylation sites of the PtAP proteins were predicted as shown in Additional file 1 and Additional file 4. Except for PtAP4, 19 and 40, the 64 PtAP proteins had the N-glycosylation sites, and all PtAP members contained the O-glycosylation sites. We further examined if some predicted $\mathrm{N}$-glycosylation sites within the crucial domains were conserved in plant APs (Fig. 9a; Additional file 4). All nucellin-like APs (category B) in Populus, grape and Arabidopsis contained the conserved Nglycosylation site between the invariant Tyr75 (pepsin numbering) and the GCGYDQ conserved sequences. Conversely, the $\mathrm{N}$-glycosylation site in the PSI domain was not conserved in Populus, grape and Arabidopsis typical APs (category A). In category $\mathrm{C}$, which had more members, the $\mathrm{N}$-glycosylation site next to the invariant Tyr75 was incompletely conserved in the GPI-anchored AP subgroup, and the other AP subgroups had similar results.

To further verify the N-glycosylation of the PtAP proteins, we generated transgenic Populus overexpressing PtAP17-FLAG and PtAP66-FLAG (OE, fused with the FLAG tag at its carboxyl terminus), respectively (Fig. 9b). Western blot analysis using anti-FLAG antibody revealed the PtAP17- and PtAP66-FLAG proteins as being $67 \mathrm{kDa}$ and $52 \mathrm{kDa}$, respectively, indicating these proteins are larger than their calculated MWs (Fig. 9c and Additional file 


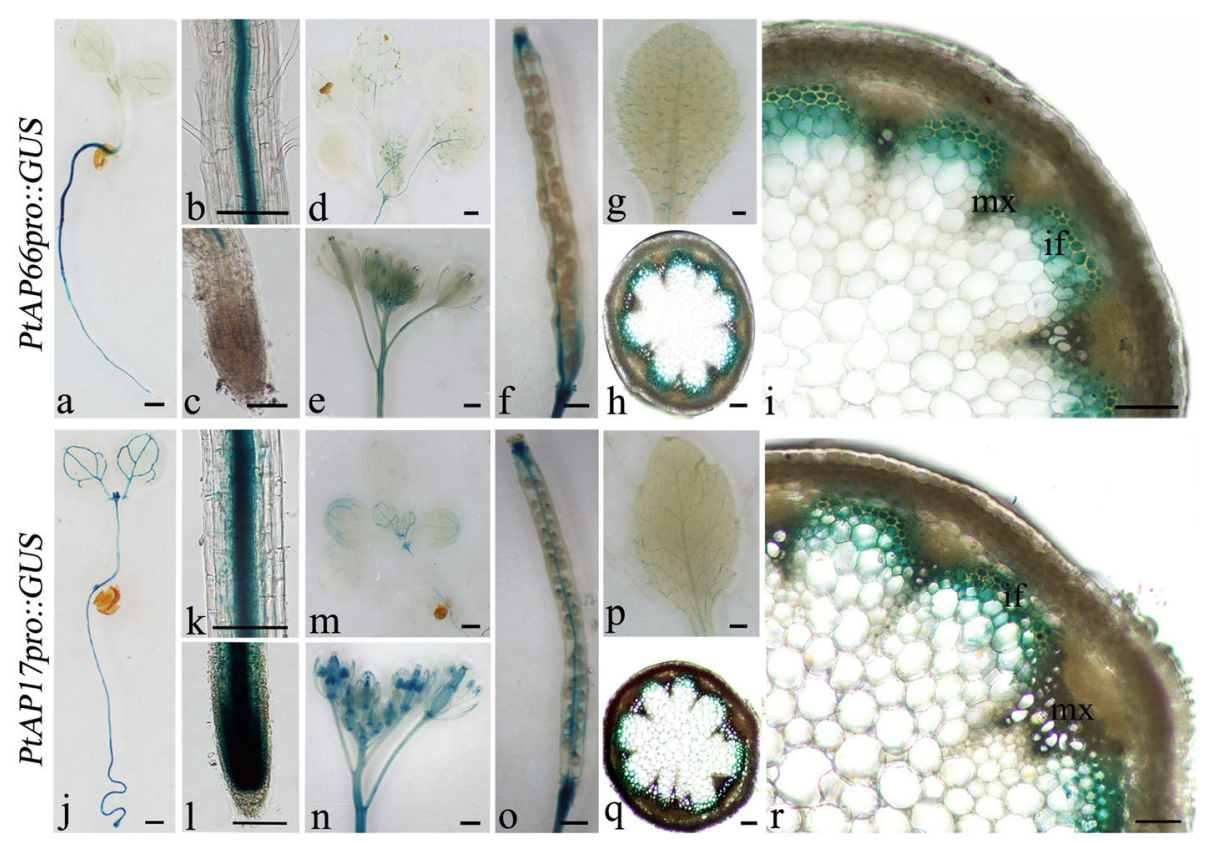

Fig. 8 Activities of PtAP66 and PtAP17 promoters in transgenic Arabidopsis. GUS staining was detected in PtAP66promoter::GUS (a-i) and PtAP17promoter::GUS (j-r) transgenic plants. (a-c, $\mathbf{j}-\mathbf{l})$ 5-day-old seedlings, their roots and root tips, respectively. (d, $\mathbf{m}$ ) Aerial parts of 2-week-old seedlings. (e-h, $\mathbf{n}-\mathbf{q})$ Inflorescences, siliques, rosette leaves and stem cross-sections of 40-day-old plants, respectively. (i, $\mathbf{r}$ ) Magnification of stem cross-sections. if, interfascicular fiber; $m x$, metaxylem. Scale bars indicate $500 \mu \mathrm{m}$ in $\mathbf{a}, \mathbf{d}-\mathbf{g}, \mathbf{j}$ and $\mathbf{m}-\mathbf{p}$ and $100 \mu m$ bars for $\mathbf{b}, \mathbf{c}, \mathbf{h}, \mathbf{i}, \mathbf{k}, \mathbf{l}, \mathbf{q}$ and $\mathbf{r}$
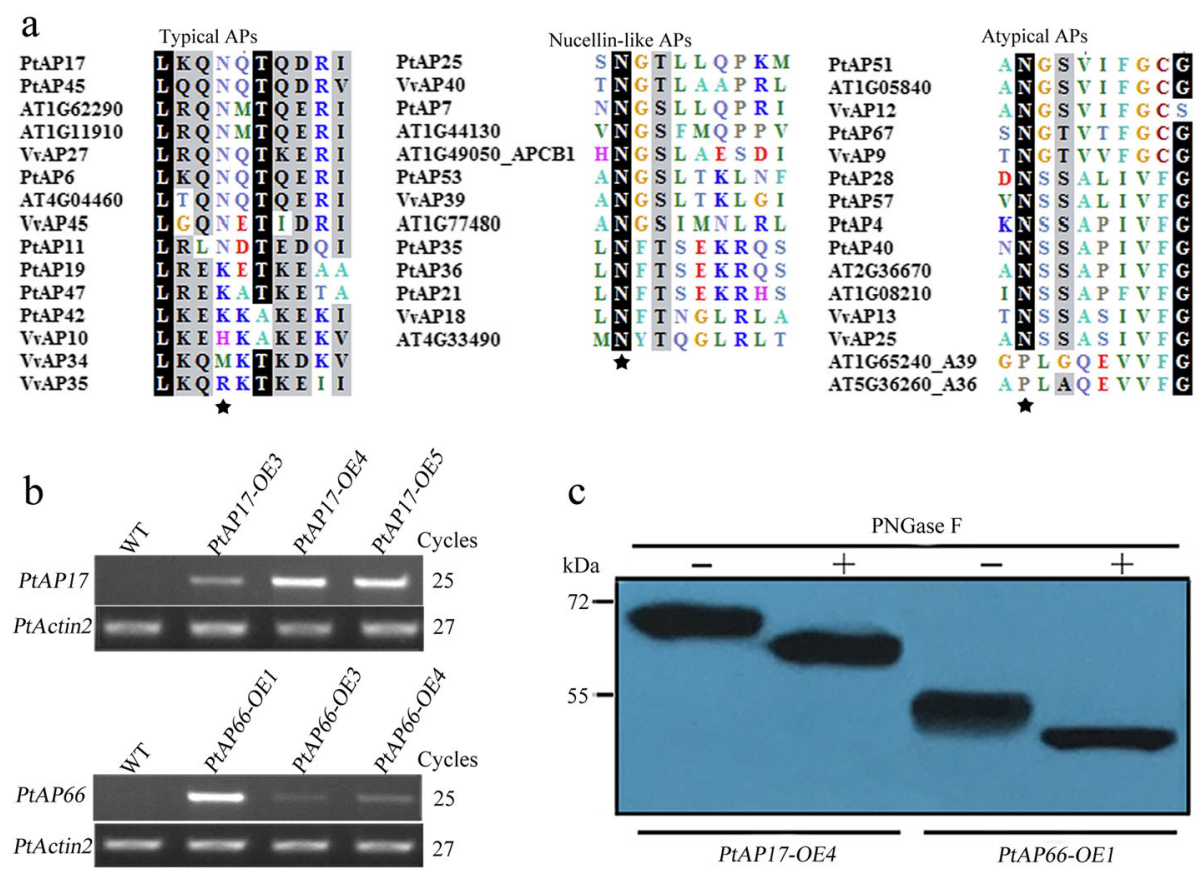

Fig. $9 \mathrm{~N}$-glycosylation analysis of PtAP proteins. a N-glycosylation site analysis of PtAP proteins from the categories A, B and C. The asterisk denotes the predicted N-glycosylation sites. Identical and conserved residues are shaded in black and gray, respectively. $\mathbf{b}$ Semi-qRT-PCR analysis of PtAP17 and PtAP66 expression in wild type (WT) and transgenic Populus. PtActin2 was used as a loading control. c Protein extracts were isolated from the leaves of PtAP17-OE4 and PtAP66-OE1 transgenic Populus, respectively. After PNGase F treatments (with or without), protein extracts were separated using 10\% SDS-PAGE and followed by immunoblotting with anti-FLAG antibody 
1). Digestion of their protein extractions with PNGase F resulted in faster protein mobility shifts of PtAP17- and PtAP66-FLAG on SDS-PAGE gels, indicating that PtAP17 and PtAP66 were N-glycosylated. Furthermore, their MWs after digestion of the PNGase F were still higher than those calculated (Fig. 9c and Additional file 1), suggesting the possible O-glycosylation of mature PtAP17 and PtAP66. These data provided the foundation for further investigations into the role of the glycosylation in the structure and function of PtAP proteins.

\section{Discussion}

Increasing evidence has demonstrated that plant APs play important roles in protein processing, stress responses, PCD and reproduction [11]. To our knowledge, there is no report on involvement of plant APs in secondary cell wall formation or wood formation. Additionally, most studies on the APs mainly have focused on herbaceous plants, especially Arabidopsis and rice [15, $16,19,24-26,42]$ and have neglected this family in tree species. In the present study, we performed a complete characterization of PtAP family in Populus, which included the phylogeny, gene organization, conserved motifs, gene duplications, expression patterns and glycosylation sites. Additionally, a set of PtAPs (PtAP5, 17,45 and 66 , etc.) were proposed to be involved in Populus wood formation, suggested by these data from tissue expression patterns, SCW-related cis-elements and PtAP $P_{\text {promoter }}:$ GUS activities. These observations provide an overall understanding of the $A P$ gene family in tree species and lay significant foundations for further investigation of their functions in tree growth and development.

In this study, we identified 67 AP genes in P. trichocarpa (Additional file 1), which were slightly more than those in Arabidopsis [6], although some gene duplication clusters were present. When we consider the ratio of 1.4 1.6 putative poplar homologs for the Arabidopsis gene [32], the number of PtAP gene family members cannot meet our expectations. The Populus genome has undergone at least three large-scaled genome-wide duplications [32], which might result in many partial and incomplete coding sequences, as noted in the 22 sequences eliminated from this study. Moreover, approximately $18 \%$ (12 of 67 ) of the PtAP genes were located outside of any duplicated blocks. Therefore, far fewer PtAP genes were observed in P. trichocarpa than we had expected. Even so, approximately $78 \%$ (52 of 67) of the PtAP genes were associated with segmental or tandem duplications, implying these genes existed as functional redundancies. For further selective pressure analysis, we found that purifying selection acted as a primary force during the AP gene family expansion in Populus, suggesting these duplicate genes might retain their ancestral functions [43].
PtAP family members within the same subgroup showed similar motifs and localization patterns (Fig. 2; Additional files 5 and 8). For example, the PtAP4, 28, 40, 51,57 and 67 were predicted to have a glycosylphosphatidylinositol (GPI) anchoring (Additional files 6 and 7), which is consistent with the A36 and A39 in Arabidopsis [26]. In addition, it is obvious that the same subgroup of PtAP genes shared similar exon/intron structures in three categories. In category $\mathrm{C}, 22$ PtAPs lacked introns and 17 PtAPs lacked 5'UTRs (Fig. 2), which have been described in Arabidopsis, rice and grape [7, 8, 44]. Possibly, the common ancestral genes have already possessed this intron/exon structure. Although the introns do not contribute to protein sequences, their relative positions provide certain clues for use in predicting how genes and their corresponding proteins evolve and further contribute to the diversification of the gene family $[45,46]$. Our data demonstrate the classification and evolutionary relationships of AP genes in Populus. This evidence also raised the possibility that plant APs in the same subgroup might have relatively conserved roles.

Gene expression patterns and function were highly correlated. PtAP family genes have diversified expression patterns, suggested by microarray data and semi-qRTPCR analysis (Figs. 4 and 5). As the orthologous gene of PCS1 that functions in embryonic development and reproduction processes, PtAP44 was preferentially expressed in catkins [25]. Some other PtAPs (AP17, 45, $64,66)$ have displayed higher transcript levels in xylems and positively correlated with stem lignified degrees. We sought these PtAPs in AspWood (http://aspwood.popgenie.org), which is a high spatial-resolution RNA sequencing database spanning secondary phloem, vascular cambium and wood tissues [47]. All of these PtAPs were highly expressed in the developing or lignified xylems (data not shown). Together, these expression data indicate that these PtAP genes should function in or associate with the SCW or PCD of wood formation. For this objective, we have filtered the SCW-related cis-elements in their promoter regions. All contained the SNBE or M46RE cis-elements (Fig. 6), which have been associated with SCW or PCD [36-39]. Furthermore, activities of PtAP66 and PtAP5 promoters in transgenic Populus (Fig. 7) suggest that they could be involved in wood formation. Interestingly, GUS staining data showed that PtAP66 was expressed in fiber cells and not in vessels, but PtAP5 was the opposite. This result is beyond our expectation because PtAP66 and PtAP5 are segmental duplication genes and have $87 \%$ amino acid sequence identities. The possibility is that the occurrence of mutations in their regulatory regions after gene duplication results in their different expression patterns. Subcellular localization prediction showed PtAP66 as a cell wall protein (Additional file 1). It is assumed that involvement of 
PtAP66 in SCW or wood formation possibly contributes to the degradation or the maturation of the proteins in the plasma membrane (PM) and/or cell wall. Presumably, these proteins may be structural wall proteins, wall modifying enzymes or PM-localized signaling proteins. Co-immunoprecipitation, yeast two-hybrid and proteomics approaches can help to seek the target proteins of PtAP66.

To date, only one type of protease, cysteine protease (XCP1/2 and AtMC9), has been demonstrated association with $\mathrm{PCD}$ and autolysis in vessels during $\mathrm{SCW}$ formation [29-31]. The understanding of PCD and autolysis in xylem fibers is limited. These PtAPs (PtAP6, 11, 17 and 45) in category A have been predicted in vacuoles and highly expressed in the lignified xylems (Figs. 4 and 5; Additional file 1), suggesting involvement of these PtAPs in PCD or autolysis during wood formation. Two SNBE cis-elements have been found in the promoter region of PtAP17 (Fig. 6). An Arabidopsis orthologous gene (At4g04460) has been suggested as a downstream target of SECONDARY WALLASSOCIATED NAC DOMAIN PROTEIN1 (SND1) and VASCULAR-RELATED NAC-DOMAIN7 (VND7) from the microarray data, which was not tested [38]. However, PtAP17 was specifically expressed in xylem fibers not vessels, as suggested by its promoter activity (Fig. 8), implying that the expression of PtAP17 should be regulated by SND1 rather than VND7, which is a direct transcriptional regulator related to SCW and PCD in vessels [48]. These results suggested that the typical aspartic protease has functional differences in Poplar and Arabidopsis during SCW formation. Nevertheless, genetic evidence of this aspect needs to be obtained to identify its upstream transcription regulators.

Glycosylation, a common post-translational modification in eukaryotes, plays a crucial role in protein structure and function [49]. Most PtAP proteins had the potential N- and O-glycosylation sites (Additional file 1), and two N-glycosylated PtAPs (PtAP17 and 66) were confirmed by experimental data in this study (Fig. 9). Since most PtAPs have the signal peptides and are locate in secretory pathways (for instance, extracellular and vacuole), they need to be glycosylated. Whether some predicted N-glycosylation sites within the crucial domains are conserved was analyzed in each category of plant APs. Nucellin-like APs (category B) in Populus, grape and Arabidopsis have been found to contain the conserved $\mathrm{N}$-glycosylation site between the invariant Tyr75 and the GCGYDQ motif, but plant APs of categories $\mathrm{A}$ and $\mathrm{C}$ have not (Fig. 9a). This suggests that different categories of plant AP proteins are diverse or confused in their employment of glycosylation modification. In previous studies, deglycosylated StAPs in Solanum tuberosum have affected subcellular accumulation in the apoplast and antifungal activity [50], and the replacement of the PSI domain of cardosin A (which has no glycosylated site) with the PSI domain of cardosin B (which has a glycosylated site) has changed the PSI mechanism of vacuolar sorting [51]. Presence or absence of the glycosylation sites in PtAP proteins could be a key structure in determining their molecular function or targeting route. In the future, the point-mutations to remove or add the glycosylation sites in PtAPs will uncover their roles in protein structure and molecular function.

Additionally, gain-of-functions of some plant APs would cause morphological changes. Misexpression of the NANA gene (nana) alters leaf morphology and causes a delayed flowering time [42]. Ectopic expression of PCS1 causes a failure in anther dehiscence and male sterility [25]. Inducible expression OsAP25 or OsAP37 exhibits extensive cell death in Arabidopsis leaves and cotyledons [24]. Overexpression of the activation tagging mutant CDR1 causes dwarfing to virulent Pseudomonas syringae [16]. However, in overexpression of PtAP17 and PtAP66 transgenic Populus, we did not observe any differences on growth and development compared with the wild type. Whether the SCW and/or PCD during wood formation is mediated by PtAPs needs to be further investigated in these transgenic Populus. Next efforts to obtain these PtAPs knockout mutants will shed light on their genetic functions and the underlying molecular mechanisms.

\section{Conclusions}

Here, we have presented an overall characterization of the AP family in Populus, including gene identification, gene structures, phylogenetic relationships, etc. Many PtAP genes have different tissue expression patterns, implying their functional diversity. Moreover, some PtAP genes (PtAP5, 17, 45 and 66, etc.) have been associated with Populus wood formation, most likely via the SCW and PCD processes, suggested by SCW-related cis-elements and PtAP promoter: $: G U S$ activity analyses. To date, the function of $A P$ gene in plants including tree in SCW development or wood formation still remains to be determined. Therefore, we next investigate the phenotypes of the CRISPR/Cas9-targeted PtAP knockout Populus trees, which can clearly reveal the roles of these PtAPs in wood formation. In short, this study provides our understanding of the AP gene family in tree and provides a better foundation for determining the functional assignments of these genes.

\section{Methods}

\section{Identification of AP genes in $P$. trichocarpa}

A total of 51 AP protein sequences in Arabidopsis [5] were retrieved and used as queries to identify AP genes in the $P$. trichocarpa genome [52] using the BLASTP programs. Subsequently, these candidate sequences were analyzed with SMART database [53] and NCBI-CDD 
[54] tools to confirm that they have the complete Asp domains (PF00026) with two conserved aspartic acid catalytic residues. Partial and defective sequences were eliminated during manual inspection. The ExPASy program (https://web.expasy.org/compute_pi/) was used to calculate molecular weights of proteins. Five toolsPlant-mPLoc [55], LocTree3 [56], ProtComp 9.0 (http:// linux1.softberry.com/), YLoc [57] and ngLOC [58]were used to predict the protein subcellular locations, and the final results were presented according to the majority. $\mathrm{N}$ - and $\mathrm{O}$-glycosylation sites were predicted in turn by NetNGlyc 1.0 (http://www.cbs.dtu.dk/services/ NetNGlyc/) and NetOGlyc 4.0 server (http://www.cbs. dtu.dk/services/NetOGlyc/), with YES and NO representing positive and negative results, respectively.

\section{Multiple sequence alignment and phylogenetic analysis} Since 22 Populus candidates lacked a complete ASP domain, they were excluded from the phylogenetic analysis and further studies. The 67 PtAPs, 30VvAPs and 51 AtAPs (pepsin-like type), barley nucellins (GenBank accession no. U87148) [59], tobacco CND41 (D26015) [60], cardoon cardosin A (CAB40134) [61] and porcine pepsin A were aligned through Clustal X 2.0 [62]. The phylogenetic trees were constructed using MEGA 5.2 with the Neighbor-Joining (NJ) method under default parameters, and bootstrap analysis was conducted using 1000 replicates [63].

\section{Genomic organization and duplication analyses}

The 67 PtAP genes were mapped on chromosomes by identifying their chromosomal locations according to the PopGenIE database [64]. Tandem duplication in the genome was defined as those closely related genes falling within $50 \mathrm{~kb}$ of one another [34]. Meanwhile, duplicated blocks were downloaded from the Plant Genome Duplication Database (PGDD) [65]. Genes were considered to have undergone segmental duplication if they were located on duplicated chromosomal segments. The number of $\mathrm{Ka}$ and Ks values was extracted from PGDD. The duplication time was estimated according to the formula: $\mathrm{T}=\mathrm{Ks} / 2 \lambda$. For Populus, the clock-like rate $(\lambda)$ was $9.1 \times 10^{-9}[66]$.

\section{Gene and protein structure analysis}

Both genomic sequences and corresponding coding sequences (CDS) of the PtAPs were loaded into the gene structure display server (GSDS) to identify the exon/intron arrangements [67]. The Multiple Expectation Maximization for Motif Elucidation (MEME) system was used to identify conserved motifs of AP protein [68]. Parameters were set as follows: the optimum motif width was set to 10-50, the maximum number of motifs to identify was set to 20 motifs, and all other parameters were defaulted. For each identified PtAP protein, putative signal peptide regions were identified using SignalP 4.1 (http:// www.cbs.dtu.dk/services/SignalP/), ASP domains using CDD and SMART, and GPI-anchor addition sites using the big-PI Plant Predictor [69]. The diagram of protein structures was constructed with DOG 1.0 software [70].

\section{Secondary wall formation related cis-elements analyses}

The $3 \mathrm{~kb}$ promoter sequences (upstream DNA sequence of the 5'-UTR) of PtAP genes (xylem eFP $>1000$ and corresponding replication genes) were scanned for the SCW-related cis-elements by manual inspection. Here 10 cis-elements were found as listed follow: SNBE (WNNYBTNNNNNNNAMGNHW), TERE (CTTNAAAGCNA), M46RE (RKTWGGTR), ACI (ACCTACC), ACII (ACCAACC), ACIII (ACCTAAC), SMRE1 (ACCAAAT), SMRE2 (ACCAACT), SMRE3 (ACCAAAC) and SMRE5 (ACCTAAT). The diagrams of these cis-elements in promoter regions were drawn using the DOG 1.0 software.

\section{Plant materials and growth conditions}

Wild type Populus trichocarpa (Nisqually-1) was planted in the greenhouse of Northeast Forestry University under conditions with a long day ( $16 \mathrm{~h}$ light/ $8 \mathrm{~h}$ dark) at $23-25^{\circ} \mathrm{C}$. More than 9 young trees (100-days old) were pooled for detecting the expression levels in different tissues and organs, and three biological replications were performed. Samples included apical bud, phloem, cambium, developing xylem, young leaf, mature leaf, petiole and root. The 1th to 6th, 9th and 12th internodes, developing xylem, cambium and phloem samples were collected as described in a previous study [71].

Arabidopsis (Arabidopsis thaliana; ecotype Columbia) plants were grown in the greenhouse ( $16 \mathrm{~h}$ of light/ $8 \mathrm{~h}$ of dark) at a light intensity of $120 \mu \mathrm{mol}$ photons $\mathrm{m}^{-2} \mathrm{~s}^{-1}$ at $22^{\circ} \mathrm{C}$. The 5 and 14-day-old seedlings for GUS staining were grown on sterilized 1/2 Murashige and Skoog plates supplemented with $1 \%$ sucrose.

\section{Microarray data analysis, RNA isolation, semi-qRT-PCR and qRT-PCR analyses}

Tissue-specific expression data on the PtAPs were downloaded from the Populus eFP browser [72]. Probe sets corresponding to PtAP genes were identified using an online Probe Match tool available at NetAffx Analysis Center (http://www.affymetrix.com/). The heat map was generated by Heat map illustrator (HemI) with the default settings [73].

Total RNA was isolated with plant RNA extraction reagents (Bio-Flux, China). For each sample, $1 \mu \mathrm{g}$ of total RNA was reverse-transcribed into total cDNAs using the PrimeScript RT reagent Kit (TaKaRa, China). The expression of the PtActin2 was used as an internal control of the same total cDNAs. Expression of the PtAPs in 
different tissues and internodes were examined by semiqRT-PCR using ExTaq (TaKaRa, China). The reaction mixture $(20 \mu \mathrm{l})$ consisted of $1 \mu \mathrm{l}$ of cDNA template, $0.5 \mu \mathrm{l}$ of each gene-specific primer $(10 \mu \mathrm{M}), 2 \mu \mathrm{l} 10 \times$ ExTaq buffer $\left(\mathrm{Mg}^{2+}\right.$ free), $2 \mu \mathrm{l}$ dNTP mixture $(2.5 \mathrm{mM}$ each), $1.6 \mu \mathrm{l} \mathrm{MgCl}$ and $0.1 \mu \mathrm{l} \mathrm{Ex-Taq.} \mathrm{The} \mathrm{PCR} \mathrm{parame-}$ ters were $94{ }^{\circ} \mathrm{C}$ for $3 \mathrm{~min}$; followed by $25-32$ cycles of $94{ }^{\circ} \mathrm{C}$ for $30 \mathrm{~s}, 58^{\circ} \mathrm{C}$ for $30 \mathrm{~s}, 72^{\circ} \mathrm{C}$ for $30 \mathrm{~s}$; and a final step at $72{ }^{\circ} \mathrm{C}$ for $7 \mathrm{~min}$. The resulting PCR products were run on a $2 \%$ agarose gel and visualized under a UV transilluminator to verify product sizes. All primers used in the present study for semi-qRT-PCR are listed in Additional file 12. Each reaction was conducted in triplicate to ensure the reproducibility of the results.

To validate the PtAP gene expression profiles, qRT-PCR analysis of these genes were performed with the same cDNA templates and primers that were used in semiqRT-PCR experiment above. The qRT-PCR experiments were performed with SYBR Green (TaKaRa, China) in the ABI Prism 7500 system (Applied Biosystems, USA) according to the manufacturer's instructions. The reaction mixture $(20 \mu \mathrm{l})$ consisted of $10 \mu \mathrm{l} 2 \times \mathrm{TB}$ Green Premix Ex Taq II (Tli RNaseH Plus), $0.8 \mu$ of each gene-specific primer, $0.4 \mu \mathrm{l}$ ROX Reference Dye II, $1 \mu \mathrm{l}$ cDNA template and $7 \mu \mathrm{l}$ distilled deionized $\mathrm{H}_{2} \mathrm{O}$. The PCR parameters as follows: $95^{\circ} \mathrm{C}$ for $30 \mathrm{~s} ; 40$ cycles of $95^{\circ} \mathrm{C}$ for $5 \mathrm{~s}, 60^{\circ} \mathrm{C}$ for $15 \mathrm{~s}, 72^{\circ} \mathrm{C}$ for $30 \mathrm{~s}$. PtActin 2 was used as an internal control and the comparative $\mathrm{Ct}\left(2^{-\Delta \mathrm{Ct}}\right)$ method was used to calculate gene expression levels. Three technical replicates were done for each sample.

\section{Plasmid construction and Agrobacterium-mediated transformation}

Genomic DNA was extracted from leaves using a plant genomic DNA extraction kit (Bioteke, China). With this genomic DNA being used as the template, approximately $3 \mathrm{~kb}$ promoter regions of PtAP17 and PtAP66 were amplified by PCR and cloned into pENTR/D-TOPO (Gateway, Invitrogen) to generate entry clones (Additional file 12). After DNA sequencing, the promoter fragments from entry clones were constructed into a Gateway binary vector pGWB3 by the LR recombination reaction. The constructs were transformed into Agrobacterium tumefaciens strain GV3101 and introduced into the Arabidopsis plants using the floral-dip method [74].

The CDS of PtAP17 and PtAP66 from Phytozome was amplified using the xylem cDNA as a template to construct overexpression vectors of pGWB11-PtAP17/ PtAP66-FLAG, and the primers are listed in Additional file 12. After determination of DNA sequencing, the resultant constructs (overexpression and promoter) were introduced into A. tumefaciens strain GV3101 for Populus transformation as described previously [75].

\section{GUS staining}

For each transgenic plant, at least six independent lines were analyzed for GUS staining. Consistent results from GUS staining in representative lines were recorded and wild-type plants negative to GUS histochemical assay were used as the controls. GUS staining was carried out as described [76]. After the GUS signal was developed, the chlorophylls of samples were cleared using 75\% (v/v) ethanol several times. The images for freehand sections of Arabidopsis stems and Populus veins were captured by a BX43 stereomicroscope (Olympus, Japan) and the other tissues were captured by SZX7 stereomicroscope (Olympus, Japan).

Deglycosylation by PNGase F treatment and western blot Transgenic plant materials were ground in liquid nitrogen and homogenized in protein extraction buffer $(50 \mathrm{mM}$ Tris- $\mathrm{HCl}, 200 \mathrm{mM} \mathrm{NaCl}, 2 \%$ SDS, $5 \mathrm{mM}$ DTT, pH 8.0). The suspensions were centrifuged at 18,000 xg for $5 \mathrm{~min}$ and the supernatants (protein extracts) were used for protein deglycosylation with/without PNGase F (New England Biolabs, UK). These treated protein extracts were then resolved in 10\% SDS-PAGE gel and transferred into PVDF membranes. Western blotting was performed using anti-FLAG antibody (Abmart, China) and Pierce ECL chemiluminescent Substrate (Thermo, USA).

\section{Statistical analysis}

Student's $t$-test was performed to determine significant difference on RT-qPCR gene expression data using statistical software SPSS19.0 (Chicago, USA). Statistically significant differences at different levels $(P<0.05$ and $P<$ $0.01)$ were marked as *and ${ }^{* *}$, respectively.

\section{Additional files}

\section{Additional file 1: Table S1. AP gene family in Populus trichocarpa. (DOCX $24 \mathrm{~kb})$}

Additional file 2: Figure S1. Multiple sequence alignment of ASP domains in 67 PtAPs. The alignment was generated using Clustal $X$ program with manual modification. The two conserved catalytic regions (DT/SG) of ASP domains and the invariant Tyr75 (pepsin numbering) are indicated. Identical and conserved residues are shaded in black and gray, respectively. (JPG $13825 \mathrm{~kb}$ )

Additional file 3: Table S2. The 22 PtAP-like genes eliminated in this study. (XLSX 14 kb)

Additional file 4: Table S3. Prediction analysis of $\mathrm{N}$ - and Oglycosylation sites in the 67 PtAPs. (XLSX $43 \mathrm{~kb}$ )

Additional file 5: Table S4. Prediction analysis of subcellular localization of the 67 PtAPs. (XLSX $36 \mathrm{~kb}$ )

Additional file 6: Figure S2. Signal peptides and conserved domains of 67 PtAPs. Phylogenetic analysis of 67 PtAPs in the left. The distribution of signal peptides and conserved domains of PtAPs. (JPG $1762 \mathrm{~kb}$ )

Additional file 7: Table S5. Backbones of 67 PtAP protein precursors. (DOCX $41 \mathrm{~kb})$ 
Additional file 8: Figure S3. Conserved motifs (1-20) identified by MEME online tool in 67 PtAPs. (JPG 1685 kb)

Additional file 9: Table S6. Estimated divergence period of PtAP gene pairs in Populus trichocarpa. (DOCX $15 \mathrm{~kb}$ )

Additional file 10: Table S7. Probes of PtAP genes in Populus trichocarpa. (DOCX $32 \mathrm{~kb})$

Additional file 11: Table S8. The eFP values of 57 PtAPs in six tissues downloaded from the Poplar eFP browser. (XLSX 13 kb)

Additional file 12 Table S9. All primers used in this study. (XLSX 10 kb)

\section{Abbreviations}

AP: Aspartic protease; BLAST: Basic local alignment search tool; CDS: Coding sequence; CRISPR/Cas9: Clustered regularly interspaced short palindromic repeats/CRISPR-associated protein-9 nuclease; eFP: Electronic fluorescent Pictograph; GPI: Glycosylphosphatidylinositol; GUS: $\beta$-glucuronidase; MW: Molecular weight; ORF: Open reading frame; PCD: Programmed cell death; PtAP: Populus trichocarpa AP; qRT-PCR: Quantitative reverse transcription polymerase chain reaction; SCW: Secondary cell wall; SDSPAGE: Sodium dodecyl sulfate-polyacrylamide gel electrophoresis; Semi-qRTPCR: Semi-quantitative reverse transcription polymerase chain reaction; SND1: Secondary wall-associated NAC domain protein 1; UTR: Untranslated region; VND7: Vascular-related NAC-domain 7

\section{Acknowledgments}

We would like to thank the reviewers and editors for careful reading and helpful comments on this manuscript.

\section{Authors' contributions}

SC, CY and YC designed the experiments. SC, MG, CW, WX, TS, GT, CZ, HC, $\mathrm{CZ}$ and $\mathrm{NI}$ performed the experiments and data analyses. SC wrote the manuscript. YC supervised the project and revised the manuscript. All authors read and approved the final version of the manuscript.

\section{Funding}

The design of the experiment and the collection of samples were supported by the Fundamental Research Funds for the Central Universities (2572016AA02). Sequencing, data analysis and writing the manuscript were supported by Project of the Natural Sciences Foundation of Heilongjiang Province (JC2016003).

\section{Availability of data and materials}

The datasets supporting the conclusions of this article are included within the article and its Additional files.

\section{Ethics approval and consent to participate}

Not applicable.

\section{Consent for publication}

Not applicable.

\section{Competing interests}

The authors declare that they have no competing interests.

\section{Author details}

${ }^{1}$ State Key Laboratory of Tree Genetics and Breeding, Northeast Forestry University, Harbin, Heilongjiang, China. ${ }^{2}$ Agriculture botany Department, Faculty of Agriculture, Tanta University, Tanta, Egypt.

\section{Received: 19 November 2018 Accepted: 3 June 2019}

\section{Published online: 24 June 2019}

\section{References}

1. Dunn BM. Structure and mechanism of the pepsin-like family of aspartic peptidases. Chem Rev. 2002;102(12):4431-58.

2. Rawlings ND, Bateman A. Pepsin homologues in bacteria. BMC Genomics. 2009:10:437.

3. Buu LM, Chen YC. Sap6, a secreted aspartyl proteinase, participates in maintenance the cell surface integrity of Candida albicans. J Biomed Sci. 2013;20:101
4. Krysan DJ, Ting EL, Abeijon C, Kroos L, Fuller RS. Yapsins are a family of aspartyl proteases required for cell wall integrity in Saccharomyces cerevisiae. Eukaryot Cell. 2005;4(8):1364-74.

5. Faro C, Gal S. Aspartic proteinase content of the Arabidopsis genome. Curr Protein Pept Sci. 2005;6(6):493-500.

6. Takahashi K, Niwa H, Yokota N, Kubota K, Inoue H. Widespread tissue expression of nepenthesin-like aspartic protease genes in Arabidopsis thaliana. Plant Physiol Biochem. 2008;46(7):724-9.

7. Guo R, Xu X, Carole B, Li X, Gao M, Zheng Y, Wang X. Genome-wide identification, evolutionary and expression analysis of the aspartic protease gene superfamily in grape. BMC Genomics. 2013;14:554.

8. Chen J, Ouyang Y, Wang L, Xie W, Zhang Q. Aspartic proteases gene family in rice: gene structure and expression, predicted protein features and phylogenetic relation. Gene. 2009;442(1-2):108-18.

9. Runeberg-Roos P, Saarma M. Phytepsin, a barley vacuolar aspartic proteinase, is highly expressed during autolysis of developing tracheary elements and sieve cells. Plant J. 1998;15(1):139-45.

10. Kervinen J, Tobin GJ, Costa J, Waugh DS, Wlodawer A, Zdanov A. Crystal structure of plant aspartic proteinase prophytepsin: inactivation and vacuolar targeting. EMBO J. 1999;18(14):3947-55.

11. Simoes I, Faro C. Structure and function of plant aspartic proteinases. Eur J Biochem. 2004;271(11):2067-75.

12. Guo RR, Tu MX, Wang XH, Zhao J, Wan R, Li Z, Wang YJ, Wang XP. Ectopic expression of a grape aspartic protease gene AP13, in Arabidopsis thaliana improves resistance to powdery mildew but increases susceptibility to Botrytis cinerea. Plant Sci. 2016;248:17-27.

13. Kato $Y$, Murakami S, Yamamoto $Y$, Chatani H, Kondo Y, Nakano T, Yokota A, Sato $F$. The DNA-binding protease, CND41, and the degradation of ribulose1,5-bisphosphate carboxylase/oxygenase in senescent leaves of tobacco. Planta. 2004;220(1):97-104

14. Huang J, Zhao X, Cheng K, Jiang Y, Ouyang Y, Xu C, Li X, Xiao J, Zhang Q. OsAP65, a rice aspartic protease, is essential for male fertility and plays a role in pollen germination and pollen tube growth. J Exp Bot. 2013;64(11): 3351-60.

15. Li Y, Kabbage M, Liu W, Dickman MB. Aspartyl protease-mediated cleavage of BAG6 is necessary for autophagy and fungal resistance in plants. Plant Cell. 2016;28(1):233-47

16. Xia Y, Suzuki H, Borevitz J, Blount J, Guo Z, Patel K, Dixon RA, Lamb C. An extracellular aspartic protease functions in Arabidopsis disease resistance signaling. EMBO J. 2004:23(4):980-8.

17. Prasad BD, Creissen G, Lamb C, Chattoo BB. Overexpression of rice (Oryza sativa L.) OsCDR1 leads to constitutive activation of defense responses in rice and Arabidopsis. Mol Plant-Microbe Interact. 2009;22(12):1635-44.

18. Breitenbach HH, Wenig M, Wittek F, Jorda L, Maldonado-Alconada AM, Sarioglu H, Colby T, Knappe C, Bichlmeier M, Pabst E, et al. Contrasting roles of the APOPLASTIC aspartyl protease APOPLASTIC, ENHANCED DISEASE SUSCEPTIBILITY1-DEPENDENT1 and LEGUME LECTIN-LIKE PROTEIN1 in Arabidopsis systemic acquired resistance. Plant Physiol. 2014;165(2):791-809.

19. Yao $X$, Xiong $W$, Ye $T, W u$ Y. Overexpression of the aspartic protease ASPG1 gene confers drought avoidance in Arabidopsis. J Exp Bot. 2012;63(7):2579-93.

20. Shen W, Yao X, Ye T, Ma S, Liu X, Yin X, Wu Y. Arabidopsis aspartic protease ASPG1 affects seed dormancy, seed longevity and seed germination. Plant Cell Physiol. 2018;59(7):1415-31.

21. Chen J, Ding J, Ouyang Y, Du H, Yang J, Cheng K, Zhao J, Oiu S, Zhang X, Yao J, et al. A triallelic system of $S 5$ is a major regulator of the reproductive barrier and compatibility of indica-japonica hybrids in rice. Proc Natl Acad Sci U S A. 2008;105(32):11436-41.

22. Ji Q, Zhang M, Lu J, Wang H, Lin B, Liu Q, Chao Q, Zhang Y, Liu C, Gu M, et al. Molecular basis underlying the 55 -dependent reproductive isolation and compatibility of indica/japonica rice hybrids. Plant Physiol. 2012;158(3):131928.

23. Phan HA, lacuone S, Li SF, Parish RW. The MYB80 transcription factor is required for pollen development and the regulation of tapetal programmed cell death in Arabidopsis thaliana. Plant Cell. 2011;23(6):2209-24.

24. Niu N, Liang W, Yang $X$, Jin W, Wilson ZA, Hu J, Zhang D. EAT1 promotes tapetal cell death by regulating aspartic proteases during male reproductive development in rice. Nat Commun. 2013:4:1445.

25. Ge X, Dietrich C, Matsuno M, Li G, Berg H, Xia Y. An Arabidopsis aspartic protease functions as an anti-cell-death component in reproduction and embryogenesis. EMBO Rep. 2005;6(3):282-8. 
26. Gao H, Zhang Y, Wang W, Zhao K, Liu C, Bai L, Li R, Guo Y. Two membraneanchored aspartic proteases contribute to pollen and ovule development. Plant Physiol. 2017;173(1):219-39.

27. Han JJ, Lin W, Oda Y, Cui KM, Fukuda H, He XQ. The proteasome is responsible for caspase-3-like activity during xylem development. Plant J. 2012;72(1):129-41.

28. Albenne C, Canut H, Jamet E. Plant cell wall proteomics: the leadership of Arabidopsis thaliana. Front Plant Sci. 2013;4:111.

29. Han J, Li H, Yin B, Zhang Y, Liu Y, Cheng Z, Liu D, Lu H. The papainlike cysteine protease CEP1 is involved in programmed cell death and secondary wall thickening during xylem development in Arabidopsis. J Exp Bot. 2018;70(1):205-15.

30. Avci U, Earl Petzold H, Ismail IO, Beers EP, Haigler CH. Cysteine proteases XCP1 and XCP2 aid micro-autolysis within the intact central vacuole during xylogenesis in Arabidopsis roots. Plant $\mathrm{J}$. 2008;56(2):303-15.

31. Bollhöner B, Zhang B, Stael S, Denancé N, Overmyer K, Goffner D, Van Breusegem $F$, Tuominen H. Post mortem function of AtMC9 in xylem vessel elements. New Phytol. 2013;200(2):498-510.

32. Tuskan GA, Difazio S, Jansson S, Bohlmann J, Grigoriev I, Hellsten U, Putnam N, Ralph S, Rombauts S, Salamov A, et al. The genome of black cottonwood, Populus trichocarpa (Torr. \& gray). Science. 2006; 313(5793):1596-604.

33. Cannon SB, Mitra A, Baumgarten A, Young ND, May G. The roles of segmental and tandem gene duplication in the evolution of large gene families in Arabidopsis thaliana. BMC Plant Biol. 2004;4:10.

34. Riechmann JL, Heard J, Martin G, Reuber L, Jiang C, Keddie J, Adam L, Pineda O, Ratcliffe OJ, Samaha RR, et al. Arabidopsis transcription factors: genome-wide comparative analysis among eukaryotes. Science. 2000; 290(5499):2105-10.

35. Dharmawardhana P, Brunner AM, Strauss SH. Genome-wide transcriptome analysis of the transition from primary to secondary stem development in Populus trichocarpa. BMC Genomics. 2010;11:150.

36. Zhong R, Ye ZH. MYB46 and MYB83 bind to the SMRE sites and directly activate a suite of transcription factors and secondary wall biosynthetic genes. Plant Cell Physiol. 2012;53(2):368-80.

37. Kim WC, Ko JH, Han KH. Identification of a cis-acting regulatory motif recognized by MYB46, a master transcriptional regulator of secondary wall biosynthesis. Plant Mol Biol. 2012;78(4-5):489-501.

38. Zhong R, Lee $\mathrm{C}$, Ye ZH. Global analysis of direct targets of secondary wall NAC master switches in Arabidopsis. Mol Plant. 2010;3(6):1087-103.

39. Ohashi-lto K, Oda Y, Fukuda H. Arabidopsis VASCULAR-RELATED NACDOMAIN6 directly regulates the genes that govern programmed cell death and secondary wall formation during xylem differentiation. Plant Cell. 2010; 22(10):3461-73.

40. Pyo H, Demura T, Fukuda H. TERE; a novel cis-element responsible for a coordinated expression of genes related to programmed cell death and secondary wall formation during differentiation of tracheary elements. Plant J. 2007;51(6):955-65.

41. Hatton D, Sablowski R, Yung MH, Smith C, Schuch W, Bevan M. Two classes of cis sequences contribute to tissue-specific expression of a PAL2 promoter in transgenic tobacco. Plant J. 1995;7(6):859-76.

42. Paparelli E, Gonzali S, Parlanti S, Novi G, Giorgi FM, Licausi F, Kosmacz M, Feil $\mathrm{R}$, Lunn JE, Brust $\mathrm{H}$, et al. Misexpression of a chloroplast aspartyl protease leads to severe growth defects and alters carbohydrate metabolism in Arabidopsis. Plant Physiol. 2012;160(3):1237-50.

43. Li S, Wang N, Ji D, Xue Z, Yu Y, Jiang Y, Liu J, Liu Z, Xiang F. Evolutionary and functional analysis of membrane-bound NAC transcription factor genes in soybean. Plant Physiol. 2016;172(3):1804-20.

44. Beers EP, Jones AM, Dickerman AW. The S8 serine, C1A cysteine and A1 aspartic protease families in Arabidopsis. Phytochemistry. 2004;65(1):43-58,

45. He Y, Ahmad D, Zhang X, Zhang Y, Wu L, Jiang P, Ma H. Genome-wide analysis of family-1 UDP glycosyltransferases (UGT) and identification of UGT genes for FHB resistance in wheat (Triticum aestivum L.). BMC Plant Biol. 2018;18(1):67.

46. Rogozin IB, Lyons-Weiler J, Koonin EV. Intron sliding in conserved gene families. Trends Genet. 2000;16(10):430-2.

47. Sundell D, Street NR, Kumar M, Mellerowicz EJ, Kucukoglu M, Johnsson C, Kumar V, Mannapperuma C, Delhomme N, Nilsson O, et al. AspWood: highspatial-resolution transcriptome profiles reveal uncharacterized modularity of wood formation in Populus tremula. Plant Cell. 2017;29(7):1585-604.
48. Yamaguchi M, Mitsuda N, Ohtani M, Ohme-Takagi M, Kato K, Demura T. VASCULAR-RELATED NAC-DOMAIN7 directly regulates the expression of a broad range of genes for xylem vessel formation. Plant J. 2011;66(4):579-90.

49. Liebminger E, Grass J, Altmann F, Mach L, Strasser R. Characterizing the link between glycosylation state and enzymatic activity of the endo- $\beta 1,4-$ glucanase KORRIGAN1 from Arabidopsis thaliana. J Biol Chem. 2013;288(31): 22270-80.

50. Pagano MR, Mendieta JR, Munoz FF, Daleo GR, Guevara MG. Roles of glycosylation on the antifungal activity and apoplast accumulation of StAPS (Solanum tuberosum aspartic proteases). Int J Biol Macromol. 2007;41(5):512-20.

51. Pereira C, Pereira S, Satiat-Jeunemaitre B, Pissarra J. Cardosin a contains two vacuolar sorting signals using different vacuolar routes in tobacco epidermal cells. Plant J. 2013;76(1):87-100.

52. Goodstein DM, Shu S, Howson R, Neupane R, Hayes RD, Fazo J, Mitros T, Dirks W, Hellsten U, Putnam N, et al. Phytozome: a comparative platform for green plant genomics. Nucleic Acids Res. 2012;40(Database issue):D1178-86.

53. Letunic I, Doerks T, Bork P. SMART: recent updates, new developments and status in 2015. Nucleic Acids Res. 2015:43(Database issue):D257-60.

54. Marchler-Bauer A, Derbyshire MK, Gonzales NR, Lu S, Chitsaz F, Geer LY, Geer RC, He J, Gwadz M, Hurwitz DI, et al. CDD: NCBI's conserved domain database. Nucleic Acids Res. 2015;43(Database issue):D222-6.

55. Chou KC, Shen HB. Plant-mPLoc: a top-down strategy to augment the power for predicting plant protein subcellular localization. PLoS One. 2010; 5(6):e11335.

56. Goldberg T, Hecht M, Hamp T, Karl T, Yachdav G, Ahmed N, Altermann U, Angerer P, Ansorge S, Balasz K, et al. LocTree3 prediction of localization. Nucleic Acids Res. 2014:42(Web Server issue:W350-5.

57. Briesemeister S, Rahnenfuhrer J, Kohlbacher O. YLoc--an interpretable web server for predicting subcellular localization. Nucleic Acids Res. 2010;38(Web Server issue):W497-502.

58. King BR, Guda C. ngLOC: an n-gram-based Bayesian method for estimating the subcellular proteomes of eukaryotes. Genome Biol. 2007;8(5):R68.

59. Chen F, Foolad MR. Molecular organization of a gene in barley which encodes a protein similar to aspartic protease and its specific expression in nucellar cells during degeneration. Plant Mol Biol. 1997;35(6):821-31.

60. Nakano T, Murakami S, Shoji T, Yoshida S, Yamada Y, Sato F. A novel protein with DNA binding activity from tobacco chloroplast nucleoids. Plant Cell. 1997;9(9):1673-82

61. Castanheira P, Samyn B, Sergeant K, Clemente JC, Dunn BM, Pires E, Van Beeumen J, Faro C. Activation, proteolytic processing, and peptide specificity of recombinant cardosin a. J Biol Chem. 2005;280(13):13047-54.

62. Larkin MA, Blackshields G, Brown NP, Chenna R, McGettigan PA, McWilliam $H$, Valentin F, Wallace IM, Wilm A, Lopez R, et al. Clustal W and Clustal X version 2.0. Bioinformatics. 2007;23(21):2947-8.

63. Tamura K, Peterson D, Peterson N, Stecher G, Nei M, Kumar S. MEGA5: molecular evolutionary genetics analysis using maximum likelihood, evolutionary distance, and maximum parsimony methods. Mol Biol Evol. 2011:28(10):2731-9

64. Sjodin A, Street NR, Sandberg G, Gustafsson P, Jansson S. The Populus genome integrative explorer (PopGenIE): a new resource for exploring the Populus genome. New Phytol. 2009;182(4):1013-25.

65. Lee TH, Tang H, Wang X, Paterson AH. PGDD: a database of gene and genome duplication in plants. Nucleic Acids Res. 2013;41(Database issue): D1152-8.

66. Lynch M, Conery JS. The evolutionary fate and consequences of duplicate genes. Science. 2000;290(5494):1151-5.

67. Hu B, Jin J, Guo AY, Zhang H, Luo J, Gao G. GSDS 2.0: an upgraded gene feature visualization server. Bioinformatics. 2015;31(8):1296-7.

68. Bailey TL, Boden M, Buske FA, Frith M, Grant CE, Clementi L, Ren J, Li WW, Noble WS. MEME SUITE: tools for motif discovery and searching. Nucleic Acids Res. 2009:37(Web Server issue):W202-8.

69. Eisenhaber B, Wildpaner M, Schultz CJ, Borner GH, Dupree P, Eisenhaber F. Glycosylphosphatidylinositol lipid anchoring of plant proteins. Sensitive prediction from sequence- and genome-wide studies for Arabidopsis and rice. Plant Physiol. 2003;133(4):1691-701.

70. Ren J, Wen L, Gao X, Jin C, Xue Y, Yao X. DOG 1.0: illustrator of protein domain structures. Cell Res. 2009;19(2):271-3.

71. Hai GH, Jia ZG, Xu WJ, Wang C, Cao SQ, Liu JW, Cheng YX. Characterization of the Populus PtrCesA4 promoter in transgenic Populus alba $\times P$. glandulosa. Plant Cell Tissue Organ Cult. 2016;124:495-505. 
72. Wilkins O, Nahal H, Foong J, Provart NJ, Campbell MM. Expansion and diversification of the Populus R2R3-MYB family of transcription factors. Plant Physiol. 2009;149(2):981-93.

73. Deng W, Wang Y, Liu Z, Cheng H, Xue Y. Heml: a toolkit for illustrating heatmaps. PLoS One. 2014;9(11):e111988.

74. Clough SJ, Bent AF. Floral dip: a simplified method for Agrobacteriummediated transformation of Arabidopsis thaliana. Plant J. 1998;16(6):735-43.

75. Li S, Zhen C, Xu W, Wang C, Cheng Y. Simple, rapid and efficient transformation of genotype Nisqually-1: a basic tool for the first sequenced model tree. Sci Rep. 2017;7(1):2638.

76. Cheng Y, Zhou W, El Sheery NI, Peters C, Li M, Wang X, Huang J. Characterization of the Arabidopsis glycerophosphodiester phosphodiesterase (GDPD) family reveals a role of the plastid-localized AtGDPD1 in maintaining cellular phosphate homeostasis under phosphate starvation. Plant J. 2011;66(5):781-95.

\section{Publisher's Note}

Springer Nature remains neutral with regard to jurisdictional claims in published maps and institutional affiliations.

Ready to submit your research? Choose BMC and benefit from:

- fast, convenient online submission

- thorough peer review by experienced researchers in your field

- rapid publication on acceptance

- support for research data, including large and complex data types

- gold Open Access which fosters wider collaboration and increased citations

- maximum visibility for your research: over $100 \mathrm{M}$ website views per year

At BMC, research is always in progress.

Learn more biomedcentral.com/submissions 